\title{
Stage I Vulvar Cancer AJCC v8
}

National Cancer Institute

\section{Source}

National Cancer Institute. Stage I Vulvar Cancer A/CC v8. NCI Thesaurus. Code C139619.

Stage I includes: T1, N0, M0. T1: Tumor confined to the vulva and/or perineum.

Multifocal lesions should be designated as such. The largest lesion or the lesion with the greatest depth of invasion will be the target lesion identified to address the highest $\mathrm{pT}$ stage. Depth of invasion is defined as the measurement of the tumor from the epithelialstromal junction of the adjacent most superficial dermal papilla to the deepest point of invasion. N0: No regional lymph node metastasis. M0: No distant metastasis. (AJCC 8th Ed.) 